\title{
The Effect of Practical Presentations' Strategy on the Achievement of the Ninth Graders Students of the Pre-Vocational Education Subject in Shobak District Schools
}

\author{
Haroon M. Al Tawarah ${ }^{1}$, Omar M. Mahasneh ${ }^{1} \&$ Nourah A. Al-Hawartheh ${ }^{1}$ \\ ${ }^{1}$ Alshobak University College, Al-Balqa Applied University, Maan, Jordan \\ Correspondence: Omar M. Mahasneh, Alshobak University College, Al-Balqa Applied University, Maan, Jordan. \\ Tel: 96-277-206-0857. E-mail: Almahasneh2007@yahoo.com
}

Received: November 23, 2016

doi:10.5539/ies.v10n5p109
Accepted: December 30, 2016 Online Published: April 29, 2017

URL: https://doi.org/10.5539/ies.v10n5p109

\begin{abstract}
The present research was conducted to evaluate the effect of using practical presentations on the achievement of the ninth graders students in pre-vocational education subject in Shobak district schools, in comparison to the prevailing method, and identify whether there are differences attributed to the gender variable. To answer the questions, the study was applied to an experimental sample in two schools of Shobak district consisting of (46) male and female students from the ninth grade for the academic year 2015/2016, who studied the pre-vocational education by using the practical presentation method, and a control group in two schools consisting of (46) students studied by using the lecturing method. The results of the study showed statistically significant differences between mean scores of members of the two groups (the experimental),male and female and (the control), male and female in the post-test application in favor of the of the experimental group that used practical presentations. The results also showed the absence of statistically significant difference at the significance level $(0.05)$ attributed to the gender variable in the achievement of the experimental group.
\end{abstract}

Keywords: strategy, practical presentation, pre-vocational education

\section{Introduction}

The modern age has witnessed a drastic change in the traditional view of the learner. The learning process shifted from just memorization of information to the thinking and inquiring. Educators have become interested in the way that enables the learner to achieve better learning, so the education activities are now focusing on the learner instead of the teacher. The pre-vocational education subject has a practical nature and a variety of areas: such as health, public safety, agriculture, industry and commerce, and others. Therefore, the study of pre-vocational educations activities is usually combined with practical performance to achieve its objectives. Accordingly, the teaching staff will adopt the methods that are commonly used. Such methods are focusing on the student in the teaching of primary grades, taking into account the learner, his inclinations, desires, and mental abilities. (Abu Sal, 1999) the teacher will practice the role of guide and mentor. He will build the teaching process on the learner's activities, which allows him to understand the concepts and ideas to make achievement in diverse fields of education, which is the target of a prominent successful teacher, using technical and technological modern methods, and following the advanced strategies and methods (Al Sayyed, 2009).

In order to face the challenges, it is necessary to use the most effective teaching strategies in education. The pre-vocational education curriculum is one of the curricula that won the interest in the educational development conference held in 1987, and the research discusses the most effective methods in improving student performance, trends, levels of thinking, and contribute to addressing the weakness of achievement among elementary stage students, and improve the quality of education (Ministry of Education, 1991). It includes functional and technical dimension, as well as the personal dimension. Each dimension includes cognitive, skill and emotional levels, combine to achieve the target, and sometimes go beyond that to build a more comprehensive concept of pre-vocational education system, which is seen as a combination of knowledge and multiple skills related to each other (Jawarneh, 2009). According to Tweissi (2004) vocational education is the vast experiences suffered by the learner in a number of vocations, or an extensive expertise in one vocation. It includes a pre-vocational educational program revolves around the main axis that could provide vocational 
information concerning the personal requirements on one part, and the different aspects of one vocation on the other part in such a manner that enables the learner to take a sound vocational decision.

Concerning practical presentation strategy, Qahtani (1999) considers it a purposeful educational activity, combining teacher performance of practical presentation with investigative represented in intellectual dialogue and questions, using some of the illustration means such as samples, drawings, or practical experience, so that to give learners the opportunity to carry out and apply some of the skills (Leslie, Roger, and Janet, 2004). The presentation is conducted in many ways; by teacher alone in most cases, or with the help of some students, making them more alert and interactive with the educational situation, or presented by a number of students on rotational basis, allowing them to interact with the educational situation. In some cases, the presentation may be practiced by a visiting guest. This type of presentation enhances students' interaction with their environment and their community, and activates classroom management. (Abu Sal, 1999)

Many studies have been conducted with a view to determining the effectiveness of the practical presentation strategy in the teaching of pre-vocational education compared to other types of activities.

Lubrano (2005) conducted a study aimed to compare the practical presentations with the lecturing method in teaching the first aid processes to primary schools in Italy. The study sample consisted of two groups; the first group studied using the theoretical lecturing method while the second studied it using practical presentation an application. The results showed that the scores of students who attended the presentations and practical applications were better than the scores of the students who have learned using the lecturing method.

Molefe et al. (2005) also conducted an experimental study aimed to compare the effectiveness of the two ways of teaching Physics experiments to eleventh graders in South African schools through scientific display method using appliances and equipment, and the results showed that there are significant differences in the students' achievement in favor of practical presentations.

Bockoven (2004) conducted a study aimed to compare the effectiveness of three methods of teaching: computer-based visual display, classroom scientific presentation, the traditional lecture in learning nervous system unit and processes for the three groups in Nebraska, USA. The results showed that there are significant differences in students' achievement in favor of classroom practical presentation.

Saegh (2000) study aimed to measure the effect of using the practical presentation on the academic achievement when teaching unit of light in physics for the second secondary grade students in three schools in the city of Mecca. The results of the study concluded that there are statistically significant differences in achievement in favor of the experimental group.

Qahtani (1999) conducted a study aimed to identify the effectiveness of practical presentation strategy on students' achievement in Biology, and their attitude towards it, and gain of knowledge by female students in the first secondary grade in Riyadh in Saudi Arabia. The results of the study indicated the presence of statistically significant differences in academic achievement in favor of the experimental group.

The previously conducted studies highlighted the positive effect of practical presentation strategy on students' achievement in Physics, Biology, first aid, etc., and focused on secondary and primary grades. This study came to address an upper basic stage in the subject of pre-vocational education, which is in bad need to apply this strategy, and perhaps this is what distinguishes the current study from other previous studies.

\subsection{Research Problem}

Given the ongoing educational development process, and the need to develop educational infrastructure, where many local studies stressed that students in general do not like the pre-vocational education subject and their scores are low, and this is what researchers noticed through their supervision and teaching. A number of methods have been used to overcome these problems, and one of the methods was focusing on using practical presentation strategy that aimed to improve the level of students achievement.

\subsection{Research Questions}

The first question: What is the effect of using an educational program based on a practical presentation on the achievement of ninth graders in the District of Shobak, compared to the prevailing method?

The second question: Are there statistical significant differences at the level of $(\alpha=0.05)$, on the achievement of ninth graders attributed to gender variable when applying the practical presentations in teaching.

\subsection{Research Limits}

1) A sample of ninth graders students in Shobak education directorate in the second semester of the academic 
year 2015/2016 and includes four schools for boys and girls.

2) Study the effect of an educational program based on practical presentation strategy when teaching two units in the pre-vocational education subject for the ninth grade in Shobak district for the second semester of the academic year 2015/2016, namely "sanitation and environment waste recycling."

\subsection{Research Terminology \& Procedure Definitions:}

First: Pre-vocational education subject: the educational course that students at the school receive in their school, and represent a set of skills and attitudes that work on the development of their abilities and preferences.

Second: Practical presentation strategy: the teacher's, specialist's or student's presentation of an educational material before students in practical situations in the form of consecutive steps.

\section{Research Methodology}

The use of quasi-experimental method through the implementation of lecture, and presentations strategies represented by the use of :(samples, items, models, movies, and experiments ) in the teaching of two units of vocational education subject (sanitation and environment waste recycling), in order to determine the effect of independent variables on the dependent variables and analysis of covariance was used to compare the results of the experimental group with the results of the control group.

\subsection{Research Population}

The research community included the ninth grader students in schools of Shobak district for the upper basic stage, about (500) male and female students for the academic year (2015/2016).

\subsection{Study Sample}

The study sample was selected from (92) male and female students by the percentage of (19\%), studying in four schools close to schools of Shobak district, the first is experimental, Mansoura basic schools for girls, and includes (21) female students and Maaz bin Jabal school for boys and includes (25) male students in the ninth grade who received teaching by practical presentation method, and the second is a control group; and comprises two schools, namely : Baqaa secondary school for girls and includes (24) female student, and al Jahir basic school and includes (22) male students, received education through the prevailing teaching method.

Table 1. Distribution of the people and members of the study sample for the students of the ninth grade For the academic year 2015/2016

\begin{tabular}{lccccc}
\hline \multirow{2}{*}{ Data } & \multicolumn{2}{c}{ Experimental Group } & \multicolumn{2}{c}{ Control Group } & \multirow{2}{*}{ Total } \\
\cline { 2 - 5 } & No. of sections & No. of students & No. of sections & No. of students & \\
\hline First & 1 & 21 & 1 & 24 & 45 \\
\hline Second & 1 & 25 & 1 & 22 & 47 \\
\hline Total & 2 & 46 & 2 & 46 & 92 \\
\hline
\end{tabular}

\subsection{Study Instruments}

The researchers adopted the following instruments:

First: Vocational lessons for "sanitation and environment waste recycling ".

Second: achievement test (pre / final).

Third: educational program

\section{Research procedures}

1) A hall for the educational operator was prepared, in addition to preparing all the needed equipments. The researcher made several meetings together the teachers of experimental study group in order to explain the strategy. The program skills, purposes and contents, the classrooms activities, evaluating methods. The researchers provided a clue to teach classroom classes. In order to determine the interior variables, four school students were selected living in the same environment, together with teachers with similar academic educational qualifications.

2) Reorganizing the educational content according to applying the strategies of the lecture and practical presentations. To be evaluated by the specialized personnel. Determine the purposes that the achievement test seeks to measure the degree of student owning it. 
3) Preparing the achievement test, where the test has passed the following steps:

a) Applying the pre-test to verify the equivalence for the experimental and test groups.

b) Applying the post-test after finish applying the program, by reapplying the pre-test on the study sample with the same previous procedure.

Table 2. Group equivalent one way analysis of variance

\begin{tabular}{lccccc}
\hline Variation source & Squares total & Degrees of freedom & Square average & $\begin{array}{c}\text { Value } \\
(\mathrm{F})\end{array}$ & Level of significance \\
\hline total & 1.837 & 1 & 1.837 & 0.089 & 0.766 \\
\hline false & 1874.878 & 90 & 20.532 & & \\
\hline total & 133863.0 & 92 & & & \\
\hline
\end{tabular}

\section{Test Validity and Reliability}

The test was viewed on the group of specialized judges, in order to reveal the range of item evaluation to the purposes that were put to be measured, after revealing the right amendment, the community included the teaching assembly members, specialized in curricula, testing and evaluating, together with sum of the teachers and supervisors. To ensure the test reliability, the test and retest method was used, which was applied on the pilot sample from the study population, outside the study sample, containing of (14) students (males \& females), with two weeks difference between the first and second test. The reliability coefficient was calculated by using alpha coefficient, which was (85.7\%) equivalent for making the study.

Table 3. The purposes that the achievement test seeks to measure the degree of students owning it

\begin{tabular}{lcc}
\hline The purposes & Question & Degree \\
\hline 1-Aknowledge some of the health plumbing spare parts & first & 5 \\
\hline 2-fix some plumbing spare parts & second & 5 \\
\hline 3-maintain some of the health plumbing spare parts (battery sink, siphon) & third & 5 \\
\hline 4-acknowledge the environmental recycling & forth & 5 \\
\hline 5-classify the recycled substance & fifth & 5 \\
\hline 6-mention the attributes that should be in the compost & sixth & 5 \\
\hline 7-determine steps to prepare the compost & seventh & 5 \\
\hline 8-clarify the importance of recycling the environmental waste & eighth & 5 \\
\hline
\end{tabular}

\section{Study Results}

\subsection{First Question}

What is the effect of using the educational program related to teaching the practical presentations in ninth grade students in Shobak conservative in comparison to the prevailed way?

The results in the Table 4 show that there are differences between the means of the students' degree on the post achievement degrees for the two groups the experimental and the controlled.

Table 4. The means and the standard deviations of the two groups members degrees on the pre and post achievement tests

\begin{tabular}{lcccc}
\hline \multirow{2}{*}{ Group } & \multicolumn{2}{c}{ Pre evaluation } & \multicolumn{2}{c}{ Post evaluation } \\
\cline { 2 - 5 } & $\mathrm{M}$ & $\mathrm{A}$ & $\mathrm{M}$ & $\mathrm{A}$ \\
\hline experimental & 37.7 & 3.8 & 83.0 & 7.3 \\
\hline control & 38.0 & 5.15 & 60.6 & 7.4 \\
\hline
\end{tabular}


Table 5. Results of ANCOVA for the answers of the study sample on the post achievement test

\begin{tabular}{cccccc}
\hline Variance resource & Sum of squares & Degree of freedom & Mean squares & value (F) & Significant level \\
\hline Practical presentations & 222.685 & 1 & 222.685 & 4.226 & 0.053 \\
\hline Pre-test & 11530.974 & 1 & 11530.974 & 218.852 & $0.000^{*}$ \\
\hline Fault & 4689.2770 & 89 & 52.689 & & \\
\hline Total & 491901.0 & 92 & & & \\
\hline
\end{tabular}

The common triple variance analysis was used as explained in Table 5. It is clear from the table that there are differences with statistical significance at the level $(\alpha \leqslant 0.05)$ between the responses of the study groups answers on the post test. The accounted value (F) was (4.226). Which means that there are differences with statistical significance between the Means of the study group students degrees who witnessed the teaching program based on the practical presentations? And members of the controlled groups, who didn't witness the teaching program, which came for the benefit of the experimental groups members on the post test. This conclusion is a result of several aspects, most distinguished are: may be first, the practical presentations and its technical characteristics make the classroom more exciting, and enhance the relationship between the teachers and the students and the study material. Second: the practical presentations raise questions and answers with students, for they develop the notice accuracy, therefore the students start to practice in the classroom. Third: this reveals that the practical presentations widen the students thinking prospects, and encourage them to participate more in the dialogue. The results agree with Al Qahtani (1999), Sanegh (2000), Bockoven (2004), Lubrano (2005), Molefe, Lemmer, and Smit (200).

\subsection{The Second Question}

Are there any differences with statistical significances on the level $(\alpha=0.05)$, among the achievements of nine grade students, related to sex variable, when teaching through the practical presentations.

Table 6. The results of $(\mathrm{T})$ test in order to test the differences between the means of the sample members' answers on the posttest related to sex variable

\begin{tabular}{lllllll}
\hline Sample type & No. & Mean & Standard deviation & T value & Freedom degrees & Significant level \\
\hline males & 47 & 72.7 & 13.6 & 0.626 & 90 & 0.533 \\
\hline females & 47 & 71.0 & 13.4 & & & \\
\hline
\end{tabular}

The results in Table 6 reveal the $(\mathrm{T})$ value reached $(0.626)$, which is not a statistical significance at the significance level $(\alpha \geq 0.00)$ which means not having differences between the experimental students degrees related to sex variable, when teaching them by using the practical presentations. This result can be explained as: whether the students are males or females, can be taught in similar school environments, supervised by their teachers who have similar qualifications, which reflect similarity in the achievement abilities and preferences. Therefore this was revealed during the supervisory visits made by the researches, which have joint stability in the social behavior, where no longer any differences between the two genders were witnessed.

\section{Study Recommendations}

1) Using the practical presentations in teaching to increase the students' achievements.

2) Using the practical presentations at schools that lack the labs.

3) Generalizing the study to include the other classes at the elementary stage, and other subjects.

4) Compare this strategy with other strategies and make the comparison.

\section{References}

Abusel, M. (1999). Introduction to the profession education. Amman: Dar Al Feker, Jordan.

$\mathrm{Al}$ Qahtani, Z. (1999). Effectiveness of the practical presentation strategy in degree obtaining the biology subject, and its trends, giving the science operations for second and first classes students at Riyadh city (Unpublished master thesis, Riyadh).

Al Sayed, M. (2009). Professional education, its principles, evaluation and teaching strategies. Amman: Wael House for distribution and publication, Amman.

Al Towaisi, A. (2004). Principles in professional education. Amman: Dar Al-Shorouq, Jordan. 
Bockoven, J. (2004). The pedagogical Toolbox Computer Generated visual, Classroom Demonstration, and Lecture. Psycholological Reports, 94(3), 967-975. https://doi.org/10.2466/pr0.94.3.967-975

Juwarna, T., \& Barakat, A. (2009). Degree of development feature at the professional educational books for the first three elementary classes at the Jordanian schools form the teachers perspectives. Damascus University magazine, 24(1+2).

Leslie, T., Roger, B., \& Janette, P. (2004). Science teaching at the high schools strategies of developing the scientific culture. Translation. Abdel Hameed, Mohammed, and others. Al Ein: university books house, United Arab Emirates.

Lubrano, R. (2005). How to Become an Under 11 Rescuer. A Practical Method to First Teach Aid to Primary Schoolchildren. Resuscitation, 64(3), 303-307.

Ministry of Education. (1991). Perspective at the elementary education in the Arabic world. Reality, development. Teacher's Thesis magazine, 10(1+2).

Molefe, N., Lemmer, M., \& Smit, J. (2005). Comparison of Computer-based and Conventional Experiments in Education. South African Jordan of Education, 25(1), 50-55.

Saegh, T. (2000). The effect of the practical presentations on the educational grades when teaching the light unit for second scientific secondary class at Mecca (Unpublished master thesis, Mecca).

\section{Copyrights}

Copyright for this article is retained by the author(s), with first publication rights granted to the journal.

This is an open-access article distributed under the terms and conditions of the Creative Commons Attribution license (http://creativecommons.org/licenses/by/4.0/). 